Vol. 4, No. 2, 2017

https://doi.org/10.23939/eem2017.02.081

UDC 368

\author{
J. Kuck \\ Doktor \\ War Studies University (Poland)
}

\title{
MODERN MANAGEMENT SOLUTIONS \\ FOR LOGISTICS, FINANCE AND HUMAN RESOURCES IN DEFENSE AND SECURITY SERVICES
}

\begin{abstract}
The aim of the paper is to present the research analysis and author's practical experiences in implementing modern IT solutions. These solutions concern, in particular building and implementing the Integrated Multilevel IT Systems for Logistics, Finance and HR operating in the defense and security services. The detailed research was also on possibility of implementing systems for product coding, electronic shopping and distance learning.

Implementing modern IT solutions should improve performance in logistics, finance and $\mathrm{HR}$ in defense and security services. The implementation of these solutions in both areas at the same time will be the most effective approach to manage the assets in the most effective way. Implemented IT solutions support rational planning, collecting, storing and using assets. Logistics management should be integrated with finances and Human resources, which facilitates delivery of necessary assets in tight quantity, quality, place and time for competitive price. This will influence achieving set aims (fulfilling tasks) in time of peace, crisis and war.

Presented solutions set general directions for informatization and involve implementation of the latest technologies (software, applications, hardware, and computer networks) and IT security. As the result the Integrated Multilevel IT Systems for Logistics, Finance and HR should be built. This system with applied planning, analytical and evaluation applications operates in real time and facilitate information exchange with systems of national economy, NATO and EU.

The base of Integrated Multilevel IT Systems for Logistics, Finance and HR is the reliable coding and identification system for all assets used and in stock. With the coding system it is possible to organize electronic shopping which help prevent corruption. The distance learning (e-learning) is another effective solution for logistics, finance and HR.
\end{abstract}

Presented possibilities of implementing new IT solutions for logistics, finance and HR are not the only possibilities new IT solutions offer. The presented ones should serve as an inspiration for decision-makers to further actions, theoretical research and practical steps.

The conducted research proved that new IT solutions influence better performance of logistics, finance and HR for defense and security services. It should also be indicated that implementation of new solutions for defense and security services is long organizational and intellectual process. It needs financial means, well prepared experts at single organizational levels where these solutions are being implemented.

Key words: Informatization, Integrated Multilevel IT Systems, coding, electronic shopping, distance learning

Modern civilization, technical and technological development are the major challenges for the systems built and implemented in the defense and security services. The aim of the paper is to present the research analysis and author's practical experiences in implementing modern IT solutions. These solutions concern, in particular building and implementing the Integrated Multilevel IT Systems for Logistics, Finance and HR operating in the defense and security services. The detailed research was on possibility of implementing systems for product coding, electronic shopping and distance learning.

The hypothesis was that the present IT systems do not meet the needs. Implementing modern IT solutions should improve performance in logistics, finance and HR in defense and security services. The implementation of these solutions in both areas at the same time will be the most 
effective approach to manage the assets in the most effective way. To verify the formulated assumptions the commercial modern IT solutions were analyzed and estimated in terms of their usefulness for the defense and security services. This analysis led to the synthetic findings about the effects of implementing these solutions. In the social science the defense and security are closely connected and implementation of the modern IT solutions for logistics, finance and HR could integrate them even more and improve their effectiveness and efficiency in time of peace, crisis and war.

1. Introduction, nature and range, and characteristic of modern solutions to aid logistics, finance and HR management.

Market economy, competition and new knowledge promote implementation of modern technologies in logistics, finance and HR. These technologies allow for collecting, transforming, storing and processing of information almost without limitation. This concerns civil economy as well as specific field, defense and security services to the same degree. Application of these solutions will result in rational planning, collecting, storing and using of the logistic assets. Logistics management should be integrated with Finance and HR to improve coordinated delivery of required capacity in the right quantity, quality, place, time and price, thus influencing defined targets (task fulfillment) in times of peace, crisis and war.

Application of the latest IT solutions which may effectively support logistics, finance and HR management will permit to:

- plan expenses rationally,

- deliver reliable information about the army resources including quantity, value, quality features of assets in real time,

- update, complete and verify information for evaluating, planning and decision making processes,

- monitor assets flow among separate departments allowing for time, place, quantity, quality and value,

- automate exchange of (official and secret) information and reporting in logistics,

- effectively record and control expenses on logistics and financial processes, corruption,

- manage e-shopping while preventing

- $\quad$ train effectively with the latest methods like distant learning (e-learning),

- achieve compatibility with the systems of national economy, NATO and EU.

The implementation of modern solutions in logistics, finance and HR will result in effective and rational assets management: collecting, organizing the data base, collecting, processing, storing and transferring information to the authorities for effective managing and rational decision making. The key point is to implement modern solutions only when all logistic, finance and HR structures, operations, management and command processes have been organized. Since modern IT solutions are of complex nature integration takes place in stages and on different levels embracing separate functional fields.

This can be depicted by 6 consecutive stages (Graph 1). The importance of the single stage changes depends on the level of design and utilization of modern IT solutions. In the field of logistics this means necessity to unify all terms, entries, product codes, limits and standards of all types, and accounts before beginning.

Unification in these fields should be the basis for "organizing" logistics and establishing connections with Finance and HR on given organizational levels in institutions, units, headquarters etc. to boost implementation of these solutions at the same time. Only stable and vivid logistics, finance and HR structures, defined processes and complete knowledge (data) base open the door to employing (executing) modern IT solutions. In particular, the requirements of logistics security in all fields and organizational levels should be precisely defined.

Describing logistics processes (in materials, technical, medical, transport, and infrastructure departments), finance and HR and creating an explicit picture (process mapping) are required for the remarkable progress in acquiring and executing modern IT solutions, firstly for a test-run and then for practical exploitation shortly after. To support logistics, finances and HR with modern technologies three basic terms have been adopted: information system, data processing system, IT system (Graph 2). 


\section{INFORMATION LINKS IN LOGISTICS, FINANCE AND HUMAN RESOURCES}

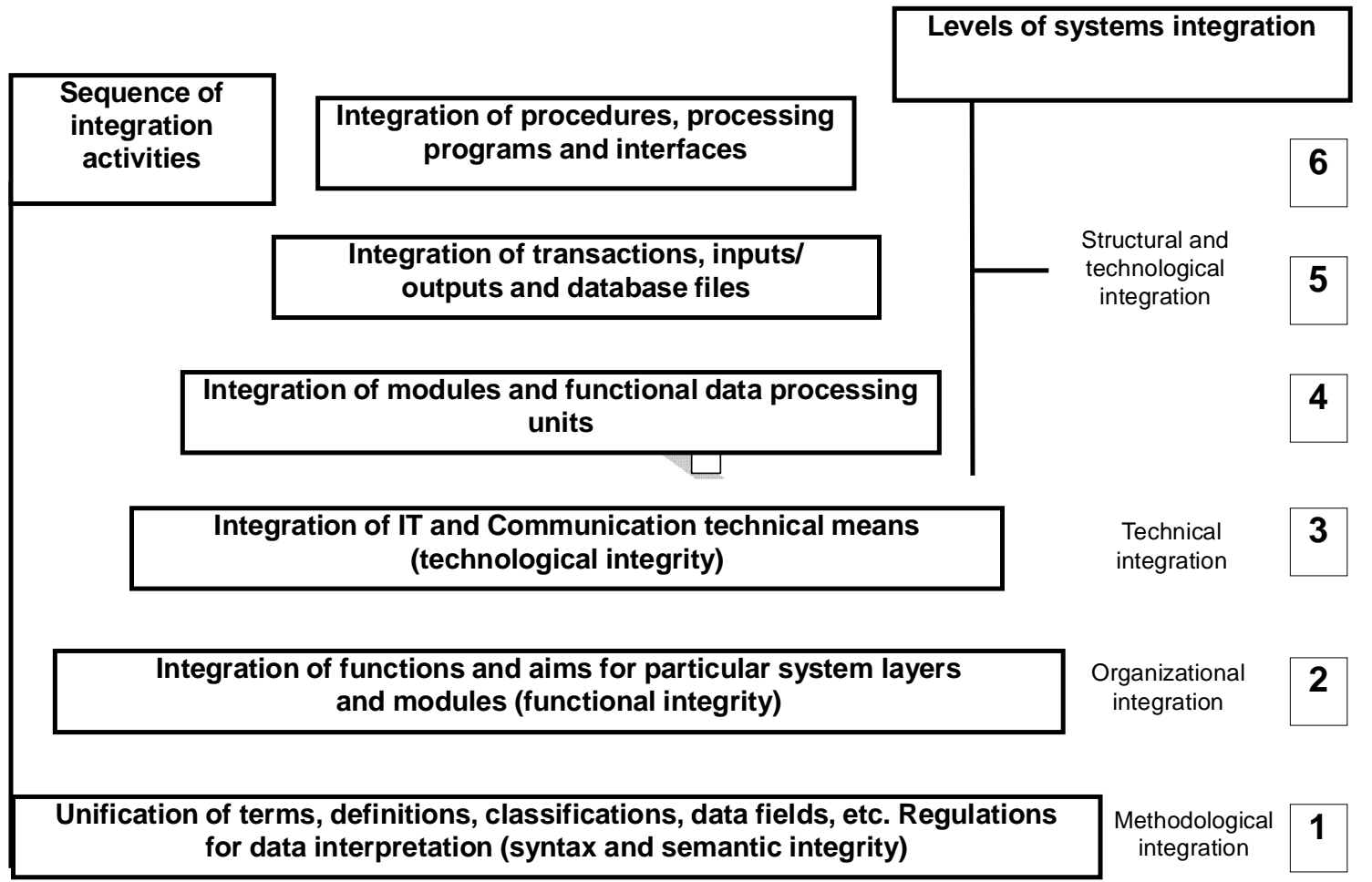

Graph 1. Stages of integration and levels of integration in management IT systems. Source: Zbigniew J. Klonowski, (Politechnika Wrocławska).

\section{INFORNAATION LINKS IN LOGISTICS, EINAANCE ANID HUIMUAN RESOURREES}

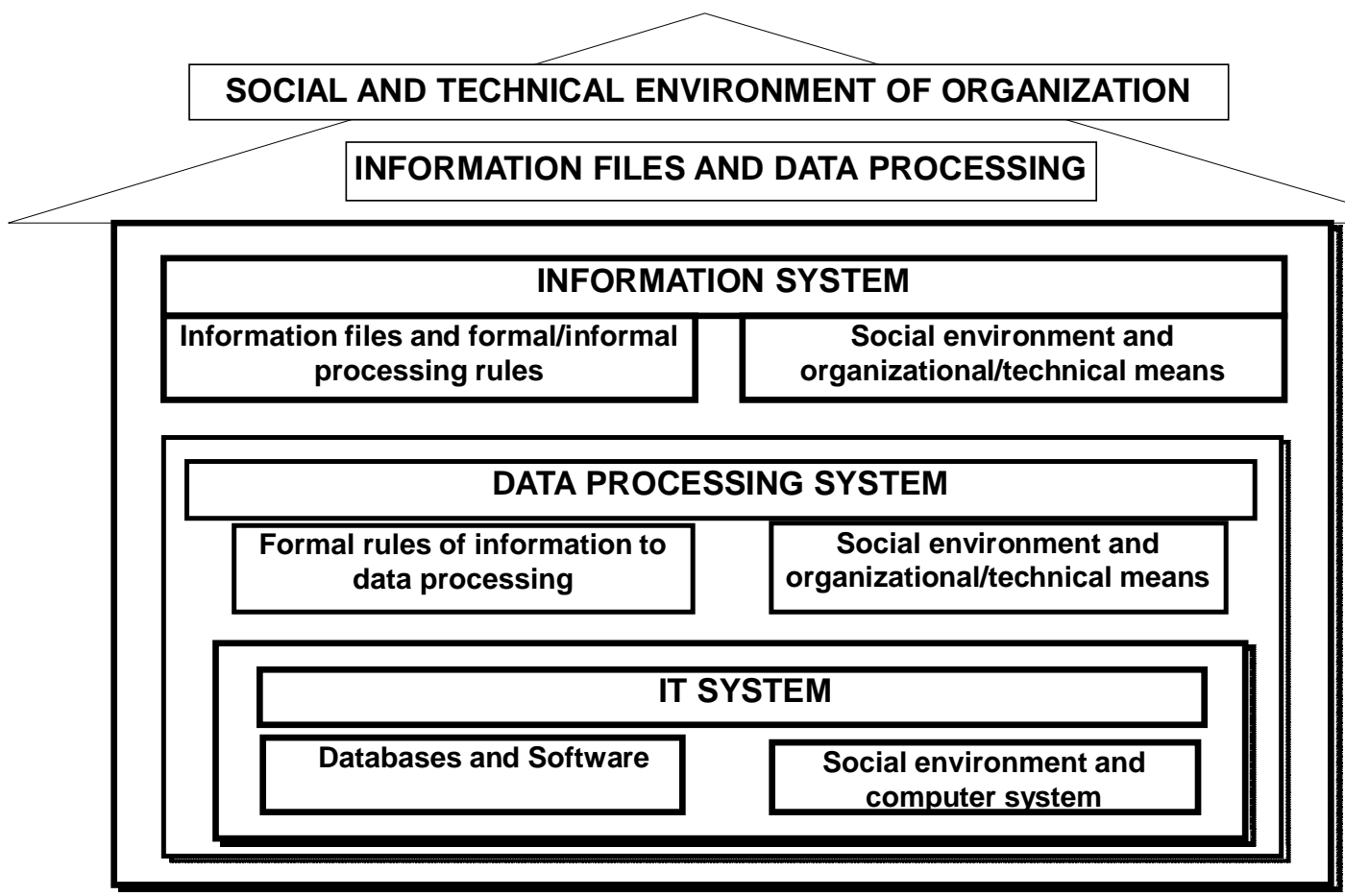

Graph 2. The general model of relations in the information system between data processing system and IT system. Source: Zbigniew J. Klonowski, Ph. D. (Politechnika Wrocławska) 
Systematization of knowledge about single relations in the information systems and organization as well as integration of logistics, finance and HR, help construct and introduction of the Integrated Multilevel IT System for Logistics, Finance and HR

The presented general outline of the suggested modern solutions for logistics, finances and HR of defense and security services proves there is an urgent need to define and apply such systems. The systems currently used are not effective in managing assets fully and rationally.

\section{Integrated Multilevel IT System for Logistics, Finance and HR}

After strategy is defined and financial means secured the introduction of IT systems in logistics may commence. This action is to embrace all organizational levels and secure all logistics fields: materials, technical, medical, transport and infrastructure. These solutions should be applied to Finances and HR as well. The main directions of informatization development include adaptation of the latest technologies (software, applications, equipment, and computer networks) and ICT systems security. The completed national product coding is an essential step in building data bases, and consequently, using the IT system for managing all assets in the defense and security services. As the end result, the Integrated Multilevel IT System for Logistics, Finance and HR should be created. This system operating in real time through adopted mechanisms for planning, analysis, auditing makes it possible to exchange information between systems of national economy, NATO and EU in times of peace, crisis and war. The Integrated Multilevel IT System for Logistics, Finance and HR needs organized and explicitly identified tasks in each field. This condition and the modern technology tools permit:

- $\quad$ extensive integration with the structures of national economy, NATO and EU;

- perfect task performance in separate fields on all organizational levels;

- ideal process management;

- rational resources and demand adjustment [1].

Moreover, stable and vivid logistics organizational structures provide the strong base necessary to build the system. Other essential elements are the range and time while implementing given levels of standardization (compatibility, interchangeability, universality) and simultaneously fulfilling tasks according to the criteria of quality, time, quantity, place and value. Clearly defined ranges of activities result in rational using of $\mathrm{HR}$ organizational structures (including knowledge, training and skills), information resources and technical infrastructure. Efficient operation of future IT system should be guaranteed by its structure composed of specific applications and technical infrastructure. The application structure may be analyzed in logical and physical terms, and the technical structure is used for collecting, processing, storing and distributing (transferring) of information. Clearly all the elements of an IT system are closely connected. Efficient and fast informatization in the defense and security services should be conducted in two stages:

- the first stage (the current task) is to identify the activities, resources and processes and then build IT systems and subsystems for logistics, finances and HR management on all organizational levels and sectors using the central data base;

- the second stage ( the consecutive task) is to build an Integrated Multilevel IT System for Logistics, Finance and HR and create networks in all organizations and institutions responsible for logistics, financial and HR security [2].

\section{Computer Aided National Product Code (NPC)}

The most crucial IT systems for logistics are systems for national product coding. So far there have been many systems used; however, none of them have included all products and equipment in stock. Computer aided universal quantity-qualityvalue accounting and material requirements, money resource planning require a reliable system to identify and categorize all resources used and in stock. Realization of these systems allows all planning, accounting and reporting systems in defense and security services to operate properly. National Product Code (NPC), at this stage of identification, is the only complete source of information about coded products. NPC Base as the information set organizes, identifies and 
categorizes products and serves as the platform to integrate all resource management systems.

Procedure of granting National Product Code consists of three stages:

Stage I - while the administrator applies for NPC it is necessary to locate the product on the proper structural level (in the vertical system) of hierarchical ranking.

Stage II - to identify the product and submit the application for NPC for the given product which is granted by the executive unit of the applicant's system.

Stage III - to grant NPC by the administration and management department currently, the Armed Forces Support Inspectorate.

The actions at these stages are performed by Computer Aided National Product Code System on the SAP R/3 platform. Operation of Computer Aided National Product Code is presented in Graph 3.

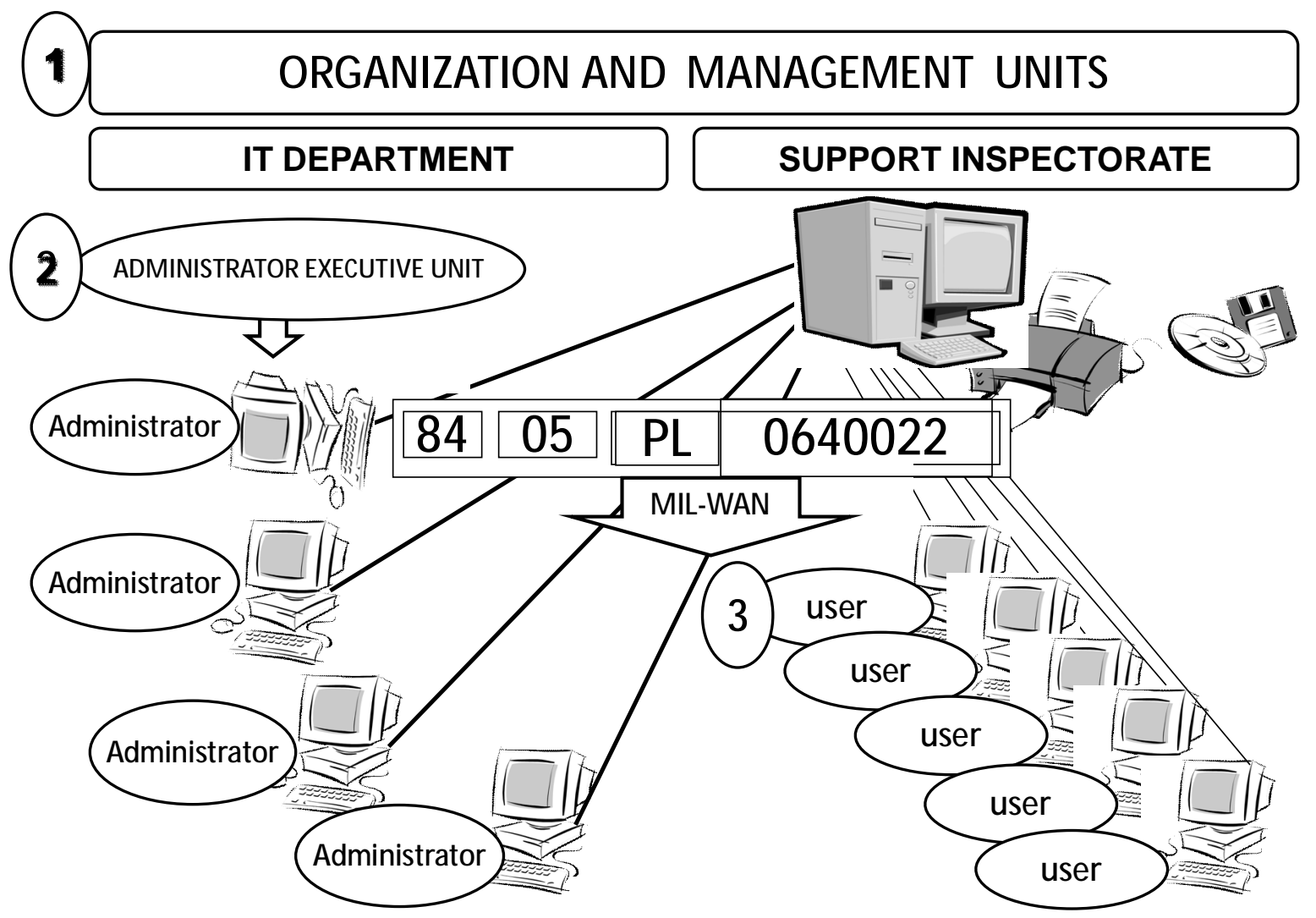

Graph 3. Operation of Computer Aided National Product Code.

4. E-commerce, e-shopping - how to prevent corruption.

The traditional forms of commercial transactions gave way to online trading which developed with the beginning of the Internet. This created limitless possibilities for quick and simple transactions between various economic entities. Nowadays e-commerce means the possibility to buy at any place and time sitting at a desk or at home. Also the e-marketplace ${ }^{15}$ and e-auctions ${ }^{16}$,

15 Electronic marketplace - virtual or online environment that allows companies-participants to conduct business electronically: buying selling, planning which are popular among the information society [3], involve purchasing, selling and delivery of products, services and information. Today technical and organizational infrastructure, also the Internet

supply chains, designing and developing products together. The source: the Internet, knowledge website, electronic marketplace. http://portalwiedzy. onet.pl/ $134004,,$, gielda_elektroniczna,haslo.html.

${ }_{16}$ Electronic auction - originates from traditional tendering (under open procedures, restricted procedures or negotiating after formal advertising for bids). Auction begins after offers (in paper form) have been submitted and assessed. It is a multiparametric biding where numerical criteria other than price are taken into consideration. The source: the Internet. 
lets companies put out to tender and so spend public money effectively. In practice modern technology adapted to tendering procedures enables participants to conduct business transactions using digital data processing and transmission via the Internet (e-mail, www search engines, links, portals, vortals and other communication means). Tendering in institutions, offices and companies is organized through e-auctions at which participants buy or sell a variety of products and services. E-auction is a four-stage process. In the first stage the invitation to the auctions are sent to all contractors whose applications have not been rejected. In the second stage the auction is open on the date stated in the invitation. In the third stage the auction is closed and results announced to the participants, and in the fourth stage the contract is signed. Contractors following the procedures receive data to $\log$ in to the system to submit further, more competitive offers by direct connection to the website at a defined time. The winner is the contractor who receives the highest number of points in the automatic evaluation of the offer.

An independent procedure for tendering is ebidding, where on the electronic tendering platform (Internet) contractors submit next, more competitive offers of delivery of products or services. This is a "round down" bidding - the winner is the cheapest offer, yet fulfilling the conditions of order specification. Tendering by ebidding is more complex than by e-auction. The first stage involves the announcement of conditions, procedures and specification of the tender on the website. In the following stages, contractors submit applications for permission to participate in electronic bidding and the customer evaluates them. Only the contractors who meet requirements are invited to the bidding. After opening, the contractors bid down the price of the order. After closing, the winner is identified and the contract is signed.

Another electronic procedure connected with tendering is dynamic purchase system, i.e. an electronic process of open tenders with a time limit. Dynamic purchase system is efficient in case of repetitive purchases or multiple purchasing of the same products or services (stationery, computers, and fuel). The regulations do not define the maximum value of purchase. In case of open tender, any criteria in conformity with the law can be adopted to select the best offer.

Electronic catalogs are also important in e-commerce. E-catalog presents information about products and services delivered by suppliers and e-market participants gathered on a given tender platform. E-catalogs may provide with the offers of products and services (product code, description, specification, measurement units, price lists, and order procedures). All elements of the offer are carefully described and the specifications may be enriched with marketing materials: graphics, sound and multimedia presentations, safety certificate and other indispensable data. The benefits of e-commerce would be difficult and even impossible to gain using traditional purchasing methods. The benefits are the following:

- reducing purchase price (commercial transactions);

- reducing labor intensity of purchasing processes;

- $\quad$ shortening the time of order completion;

- more choices (many suppliers and wider range of products);

- automatization of order placement and completion; processes;

- permanent monitoring of purchasing processes;

- reducing office management and equipment costs;

- $\quad$ reducing the number of personnel;

- shortening the distribution channels (simplifying circulation of documents);

- simplifying the customer service by collecting information about customer preferences easily;

- introducing new methods of promotion and advertisement;

- reducing stock;

- $\quad$ placing and modifying offers quickly;

- current information about the product availability;

- $\quad$ quick and widespread distributing of the information about products, prices on the Internet sites and relatively low prices of building and reengineering of services; 
- $\quad$ storing and archiving the transactional data for a given period of time;

- clear transactional procedures eliminating corruption;

- $\quad$ saving time and decreasing the need to travel (physically) to collect information and compare products and services.

The EU directive of 2010 about e-tender and e-shopping defines the requirements that auctions, tenders and purchases should be organized via the Internet since 2010. In Poland the institutions, offices and companies may do e-shopping via Polish Tender Platform (PPP) located in Polish Securities Manufacturing Company. Implementation of this solution results in reduction of cost and labor intensity of purchasing processes, the possibility to conduct modern financial analysis, the guarantee of clear transactional procedures, and elimination of corruption. Through this process, it is possible to save 10-20\%. A coding system at electronic auctions ensures safety and reliability of transactions documented with the electronic signature. The sooner these solutions are employed the more robust economic and organizational benefits may be obtained.

\section{Distance learning (e-learning) for} Logistics, Finance and HR purposes.

Effective training of staff responsible for safety may be completed through various methods. One of them is e- learning (distance learning). The Internet creates favorable conditions for modern methods to be introduced to already existing educational model and vocational training. Distance learning is a process where the learner and the tutor are at a certain distance from each other [4]. There are a lot of definitions of distance learning. Mirosław Kubiak provides one: distance learning is the method adopted for teaching process when teachers and course participants (students) are at certain distance from one another and they are not at the same place. Information is passed on by traditional communication means as well as modern information technologies [5]. The most important benefits of adopting e-learning methods are:

- ability to provide well - prepared materials at the right time and place for a student;
- $\quad$ easily accessible course for participants on the levels of creating, distributing, assigning and controlling;

- free access to collect teaching materials and free information exchange at any place by any number of students;

- central coordination and management of courses;

- standardization of knowledge and information resources;

- relevant teaching materials (may be easily updated personally or by another expert);

- $\quad$ teaching management system informing students about introduced changes;

- enhanced efficiency of training processes by introducing appealing alternative teaching methods;

- possibility to report and analyze the individual student learning period;

- extending, completing, and correcting knowledge acquired through traditional means;

- $\quad$ increasing new skills easily by applying blended learning method;

- high level of effectiveness by adopting testing tools and certificates;

- free contact with an expert;

- discreet and stress-free training process for a student;

- better use of resources thanks to detailed analysis of individual and group competence and skills;

- training process matching individual needs of participants;

- cost reduction of preparing teaching materials by using tools for creating individual courses;

- financial benefits thanks to reducing business trip expenses, eliminating travelling and accommodation costs;

- better use of technical and academic capacity of universities and scientific institutes.

Using this method is extremely positive for the people who want to extend their knowledge and are determined enough to climb the career ladder. This may serve as a component of traditional methods of teaching for those who use new knowledge and want to develop their qualifications. 


\section{J. Kuck}

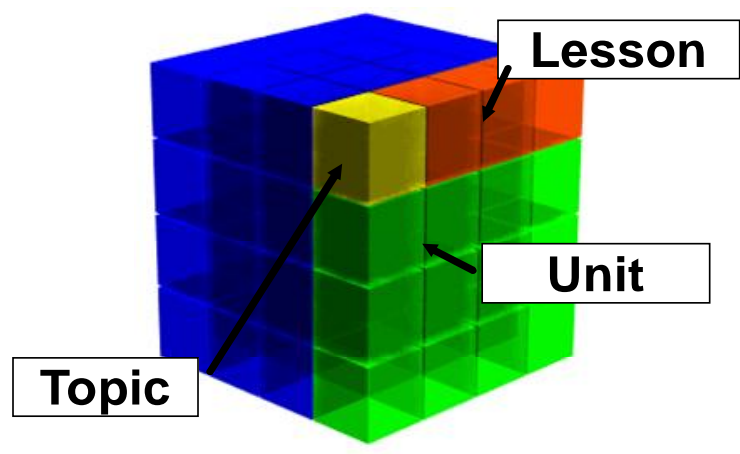

Graph 4. Structure of the course in library of objects.

Training and e-learning courses are constructed of modules called teaching objects. In the structure of the course (Graph 4) they are subject to units of higher rank - lessons and lessons to units. Each element is a complete, independent course stage with its own defined targets, training activities and testing elements. Such flexibility allows new materials to be composed, modified and created freely.

E-learning in defense and security services does not differ much from methods in civil service. This is a solution which makes it possible to run courses (teach) through quick and efficient transfer of knowledge from supplier (coach, teacher) to customer (soldier, officer, worker) and to apply it simultaneously at any time and place. Adopting technological solutions to create and distribute knowledge (data and information) contributes to gaining more knowledge by course participants in many different fields.

Thanks to these solutions it is possible to define what a given soldier, officer, or worker with certain responsibilities should know and which courses should they participate in. The spectrum of e-learning activities in above-mentioned organizations can be analyzed in terms of three different dimensions: people, knowledge and communication [6]. The most popular e-learning platforms on the market are those with required functions. It is easier and cheaper to apply the already existing functions than design them individually.

In practice the Moodle platform (Modular Object Oriented Distance Learning Environment) meets the above discussed requirements. Since it is used in the teaching process in many civil universities, the Moodle may be adopted in the defense and security services as well. This platform is a modular, dynamic, object-oriented teaching environment designed to create and run courses via the Internet.

The listed examples do not constitute all the possibilities, ways, fields or places where e-learning may be beneficial. The question of where to locate people responsible for preparation, collection and distribution of teaching materials arises. One of the suggestions is to introduce this method of teaching quickly using the academic and technical capacity. Research studies and published papers would make sufficient teaching materials in this case. Another suggestion is to commission experts in logistics to design teaching topics [7] In reality distance learning is an educational not a technical issue [8]. The proposed distant learning solutions meet expectations and it may be stated that they are not only a fad but urgent need and even a necessity. The point is to be well prepared both technically and mentally.

\section{Summary}

Field analysis of should inspire decisionmaking bodies to further research and to take practical actions leading to applying these solutions for logistics, finance and HR. The issues discussed are sufficient source of knowledge about the actual and current stage of informatization and in what way the implementation of modern IT solutions should be planned and conducted. Using modern solutions makes it possible to plan and raise financial resources more effectively for enterprises to create more efficient access to information. Information should be collected, stored and distributed in real time on the proper decisionmaking level and with proper security precautions. Streamlining of organizational and functional structures and implementing an IT system should be correlated. Defined structure- defined system. Strategic targeting, which the Integrated Multilevel IT System for Logistics, Finance and HR depends on, should involve:

- completion of product coding (coding, and identifying products on the level of warehouse management);

- employing the automatic exchange of open and secret information using stationary and field networks taking proper network security precautions; 
accounting;

- integration of quantity-quality-value

- building IT structures for logistics, finance and HR on the separate organizational levels;

- $\quad$ obtaining the cooperation and ensuring compatibility of logistics systems with national economy systems, NATO and EU;

- $\quad$ securing financial means by task budgeting.

The aim of the research was completed. After the analysis had been carried out the author presented modern IT solutions that can be efficiently and fast implemented to manage the assets rationally. The proposed IT solutions for the commercial market help to gain competitive advantage. The formulated hypothesis was proved since modern IT solutions enhance performance in logistics, finance and HR of the defense and security services. The implementation of these solutions in both areas at the same time will be the most effective approach to manage the assets in the efficient way. Moreover, it should be indicated that implementation of modern solutions for supporting logistics, finance and HR in the defense and security services is a long organizational and intellectual process. This requires considerable financial support and well prepared workers (experts) on given organizational levels where the changes are in process. In order to achieve success, aware and determined managers are indispensable. With a long-term vision and practical actions, it is possible to adopt modern solutions of the 21 century.

\section{References}

1,2. Kuck J., Strategia informatyzacji logistyki w resorcie obrony narodowej [Myśl wojskowa $\mathrm{nr}$ 2/Z] MON Warszawa 2006. s. 45

3. Chmielarz W.; Handel elektroniczny nie tylko $w$ gospodarce wirtualnej, Wydawnictwa Naukowe WZ UW, Warszawa, 2001: Information society or Virtual society is a large social grouping sharing the same distinctive interests, culture, convictions, needs and lifestyle, concentrated in the virtual space of network structure, irrespective of a physical position of its individuals.

4. Distance Learning Glossary, http://www.elearners. com/ resources/ glossary.asp http://www.usdla.org/distancelearning-glossary/

5. Kubiak Mirostaw J.: Wirtualna edukacja, s. 11. Warszawa 2000. Wydawnictwo "MIKOM

6. Potęga możliwości, e-learning $w$ codziennej praktyce liderów. Materiaty $z \quad$ III Międzynarodowej konferencji e-learningowej. Warszawa 2008.

7. Gonczarek B, Kuck J. : E-learning nauczanie na odległość na potrzeby logistyki. [w]: Perspektywy informatyzacji logistyki $w$ Wojsku Polskim. SGWP Logis. Wewn. 4/2006.

8. Oblinger D. Kidwell J., (2000), Distance learning are we being realistic?, "Educause Review" Vol. 35 Issue 3 